\title{
Factors Affecting the Quality of Biodiesel from Palm Fatty Acid Distillate at Palm Oill Refining Plant
}

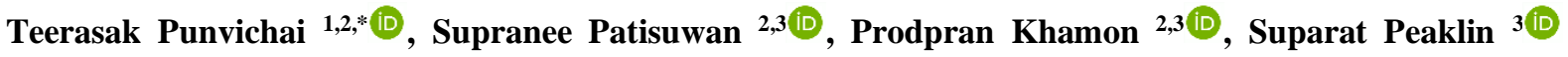 \\ Yutthapong Pianroj 2,3 (D) \\ 1 Faculty of Innovative Agriculture and Fisheries Establishment Project, Prince of Songkla University, Suratthani campus, \\ Suratthani, Thailand, 84000 ; teerasak.p@psu.ac.th; teerasak.punvichai@yahoo.com (T.P.); \\ 2 Integrated High-Value Oleochemical Research Center, Prince of Songkla University, Suratthani campus, Suratthani, \\ Thailand, 84000 \\ 3 Faculty of Science and Industrial Technology, Prince of Songkla University, Suratthani campus, Suratthani, Thailand, \\ 84000; supraneepatisuwan@gmail.com (S.P.); $\quad$ prodpran.k@psu.ac.th $\quad$ (P.K.); $\quad$ suparat.n@psu.ac.th $\quad$ (S.P.); \\ yutthapong.p@psu.ac.th (Y.P.); \\ * Correspondence: teerasak.p@psu.ac.th; teerasak.punvichai@yahoo.com (T.P.);
}

Scopus Author ID 16507462500

Received: 12.10.2021; Revised: 15.11.2021; Accepted: 18.11.2021; Published: 9.12.2021

Abstract: A study on factors affecting biodiesel quality of agricultural by-products, namely palm oil derived using palm fatty acid distillate (PFAD), collected from the Oleen Palm Oil industrial refining plant. This PFAD showed free fatty acid content and a saponification value of $88.4 \%$ and $204 \mathrm{mg}$ $\mathrm{KOH} / \mathrm{g}$, respectively. An acid catalyst was successfully used to produce biodiesel in the esterification reaction, and a 97.11\% conversion to biodiesel based on the European Standard EN 14214:2003 was achieved under the conditions (PFAD to methanol molar ratio 1:3.71 with $1.834 \% \mathrm{H}_{2} \mathrm{SO}_{4}$ catalyzed at $121{ }^{\circ} \mathrm{C}$ for 15 minutes). Overall, this novel process achieved highly enhanced FAME $(95.82 \%$ to $97.31 \%$ ) with a significantly increased reaction time (10 to 30 minutes) and catalyst requirements (1.834 $\left.\% \mathrm{H}_{2} \mathrm{SO}_{4}\right)$.

Keywords: palm fatty acid distillate; esterification; biodiesel.

(C) 2021 by the authors. This article is an open-access article distributed under the terms and conditions of the Creative Commons Attribution (CC BY) license (https://creativecommons.org/licenses/by/4.0/).

\section{Introduction}

Thailand is one of the productive palm oil producers in the world. In the year 2018, 15.53 million tonnes of palm oil products from Thailand were produced [1]. It is reported that about 776,750 tonnes of Palm fatty acid distillate (PFAD) were produced in Thailand during the palm oil refining process (Figure 1). PFAD containing very high free fatty acids (FFA) is a by-product of the palm oil purification process [2-4]. It is generally used in several industrials (cleaners, animal feeds, plastics). Moreover, other researchers reported in the literature biodiesel production using PFAD [4-6]. The biodiesel can be synthesized by esterifying lowquality oils containing high FFA (> 90\%) palm fatty acid with alcohols, as shown in Figure 2. Therefore, there is a need for innovation. The PFAD is generally used in nonfood applications such as soap making and is also used as a power source in power plants and industrial boilers $[2,3]$. To produce biodiesel from high FFA oil, esterification has been frequently used to convert the FFA content in oil to esters $[6,7]$. However, excess alcohol and catalyst loading must be used in the acid-catalyzed esterification to obtain high purity and yield of biodiesel from high FFA [8-10]. In the esterification step, the generated wastewater hinders the extent of esterification, and the methanol and sulfuric acid are diluted by the generated wastewater [8- 
11]. PFAD samples are potential substrates for biodiesel fuel production, biochemical, soap, and oleochemical $[2-4,13]$. Thailand has a great advantage in developing biodiesel production since PFAD can be used as feedstocks for biodiesel production.

This study aims at factors affecting biodiesel production quality for value-adding PFAD from the palm oil refining plant at Oleen Co., Ltd.

\section{Materials and Methods}

\subsection{PFAD samples analysis.}

The samples of PFAD were collected at the Oleen Palm Oil plant (Samutsakorn, Thailand) and stored at room temperature $\left(26 \pm 2{ }^{\circ} \mathrm{C}\right)$. The PFAD was analyzed for free fatty acid (FFA) by AOCS Ca 5a-40 [14], saponification value by AOCS Cd 3-25 [14], and fatty acid composition was determined by gas chromatography (AOCS Ce 1-62) [14].

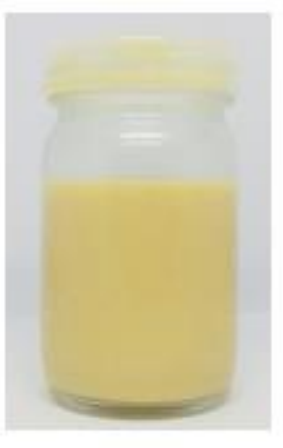

(A)

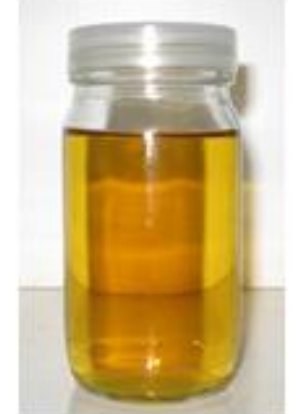

(B)

Figure 1. Palm Fatty Acid Distillates (A) Biodiesel PFAD (B).

$\begin{array}{ccccc}\text { HOOCR' } & \mathrm{ROH} & + & \text { RCOOR } & \mathrm{H}_{2} \mathrm{O} \\ \text { free fatty acid } & \text { alcohol } & \text { biodiesel } & & \text { water }\end{array}$

Figure 2. Esterification Reaction.

\subsection{Experimental biodiesel production.}

The esterification of PFAD was carried out using reactor 5 liters per bath for biodiesel production from palm fatty acid distillate with high pressure (Figure 3).
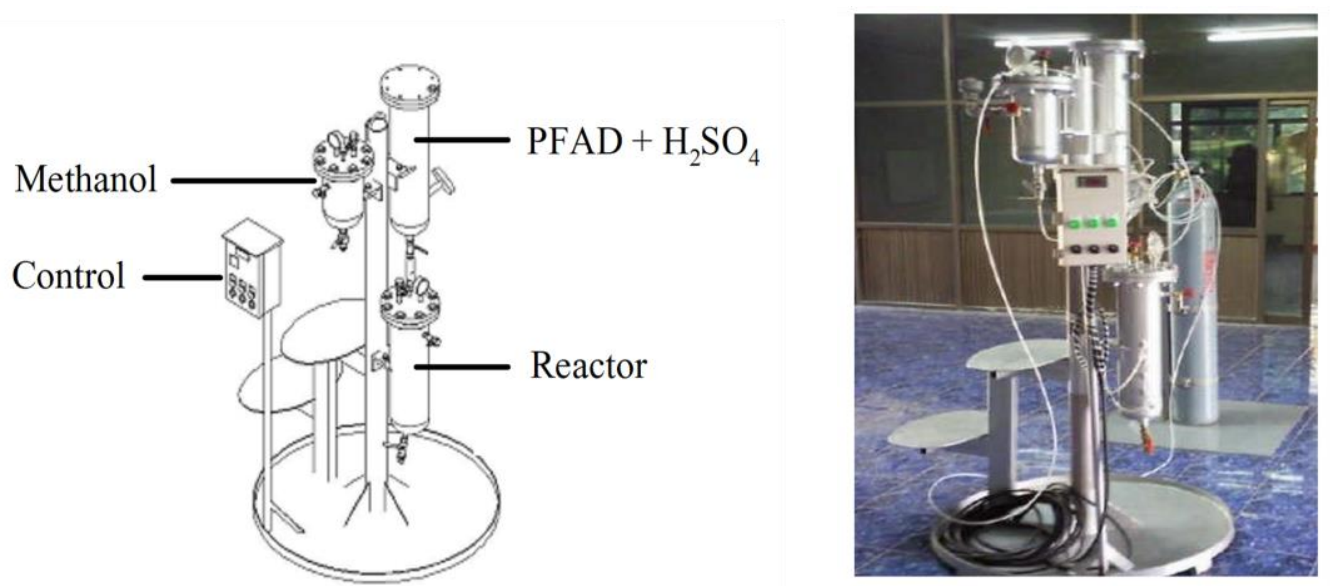

Figure 3. Biodiesel esterification reactor 5 liters. 
Additionally, the percentage conversion of FFA in the processes was compared under similar reaction conditions such as methanol to PFAD molar ratio, acid catalyst dosage, temperature, and reaction time.

\subsubsection{Effect of methanol for biodiesel production from PFAD.}

Biodiesel was produced from the PFAD from the palm oil refining plant at Oleen Co., Ltd., single-step esterification method. In this, esterification process the PFAD was mixed with methanol in the ratio of 1:1.24, 1:2.47, and 1:3.71 (molar ratio). $98 \%$ concentrated sulfuric acid $(1 \% \mathrm{v} / \mathrm{v}$ PFAD) was added as a catalyst to enhance the esterification reaction to the mixture. The mixture of PFAD, methanol, and the catalyst was allowed to react in the reactor at $121{ }^{\circ} \mathrm{C}$ for 30 minutes under high pressure of 15 bar approximately. The mixture obtained consisted of two layers; the upper layer of methanol and sulfuric acid and the lower layer consisting of the esterified oil. With the help of a separating funnel, the esterified oil was separated from the methanol and other impurities. Finally, sodium sulfate was added to methyl ester to remove water vapors and then filtered with a filter paper. The reaction yield was analyzed for FFA by AOCS Ca 5a-40 [14], and the percent conversion of esterification was calculated. Percent conversion was measured by total free fatty acid before esterification and after esterification.

$\begin{array}{ll} & \text { Conversion }(\%)=[(\mathrm{a}-\mathrm{b}) / \mathrm{a}] \times 100 \\ \text { When; } & \mathrm{a}=\text { total free fatty acid before esterification } \\ \mathrm{b}=\text { total free fatty acid after esterification }\end{array}$

The reaction runs and FFA analysis were done in triplicate, and the results are expressed as mean value and standard deviation (SD). Results were analyzed statistically using SPSS software version 21.0. Data were tested by analysis of variance ANOVA and evaluate significant difference by LSD at the $\mathrm{P}=0.05$ level.

\subsubsection{Effect of acid catalyst dosage for biodiesel production from PFAD.}

Applying the procedure detailed in section 2.2.1, the product containing the highest percentage of conversion was prepared again under the corresponding suitable conditions. Other batches of biodiesel were prepared under the same conditions as above (maximum percent conversion) and differing loads of acid catalyst dosage $(0.611,1.223,1.834$, and 2.445 $\%)$. The reaction yield was analyzed for FFA by AOCS Ca 5a-40 [14], and the percent conversion of esterification was calculated. Results were analyzed statistically using SPSS software version 21.0. Data were tested by analysis of variance ANOVA and evaluation of significant difference by LSD at the $\mathrm{P}=0.05$ level.

\subsubsection{Effect of temperature and time for biodiesel production from PFAD.}

By applying the procedure detailed in sections 2.2.1. and 2.2.2, the product containing the highest percentage of conversion was prepared again under the corresponding suitable conditions. Other batches of biodiesel were prepared under the same conditions as above (maximum percent conversion) and differing loads of temperature $\left(70,100,121\right.$, and $130{ }^{\circ} \mathrm{C}$ ). The reaction yield was analyzed for FFA by AOCS Ca 5a-40 [14], and the percent conversion of esterification was calculated. Results were analyzed statistically using SPSS software 
version 21.0. Data were tested by analysis of variance ANOVA and evaluation of significant difference by LSD at the $\mathrm{P}=0.05$ level.

Then the highest percent of conversion was prepared again under the corresponding suitable conditions and differing loads of time (10, 15, 20, 25, and 30 minutes). The reaction yield was analyzed for FFA by AOCS Ca 5a-40 [14] and the calculated percent conversion of esterification. Each prepared biodiesel was then placed in a closed Eppendorf tube and stored for one week in refrigeration (below $10 \pm 2{ }^{\circ} \mathrm{C}$ ) before measuring the fatty acid methyl ester (FAME) content by a TLC-FID analyzer. Results were analyzed statistically using SPSS software version 21.0. Data were tested by analysis of variance ANOVA and evaluation of significant difference by LSD at the $\mathrm{P}=0.05$ level.

\subsection{Determination of FAME.}

Fifty microliters of the sample after esterification were mixed with $50 \mu \mathrm{L}$ of chloroform, and the percentage of FAME was analyzed by a TLC-FID analyzer (IATROSCAMTM MK-5, Iatron Laboratories Inc., Tokyo, Japan).

\section{Results and Discussion}

\subsection{Composition of PFAD.}

PFAD and crude palm oil (CPO) were analyzed for FFA and saponification. Acidity and saponification value was $88.5 \pm 0.1 \%$ and $204.2 \pm 1.1 \mathrm{mg} \mathrm{KOH} / \mathrm{g}$ oil, and $4.6 \pm 0.2 \%$ and $200.5 \pm 1.1 \mathrm{mg} \mathrm{KOH} / \mathrm{g}$ oil for PFAD and CPO, respectively (Data not show). Fatty acid compositions of samples are given in Table 1. PFAD and CPO are confirmed as sources of saturated and monounsaturated fatty acids.

The analyzed fatty acid composition of the oils used in this study (Table 1) is consistent with published values. PFAD and CPO contain high percentages of palmitic (16:0) and oleic (18:1) acids as major components. PFAD and CPO show a higher proportion of saturated fatty acids (56.9 and 48.0 respectively) compared to unsaturated fatty acids. But CPO contains less palmitic acid (41.49\%) than PFAD (49.46\%). PFAD contains $35.0 \%$ of monounsaturated fatty acids, including $33.95 \%$ of oleic (18:1) acid. The percentage of oleic acid in CPO is higher than in PFAD, and the same applies to polyunsaturated fatty acids. Subsequently, the percentage of trans fatty acid in PFAD is higher than in CPO, probably because of the catalysis of isomerization by the activated bleaching clay or high temperature due to physical refining [2-4].

Table 1. Fatty acid composition of PFAD and reference CPO.

\begin{tabular}{l|l|l} 
Fatty acid & PFAD $(\boldsymbol{\%})$ & CPO $(\boldsymbol{\%})$ \\
\hline Saturated fatty acid & $\mathbf{5 6 . 9}$ & $\mathbf{4 8 . 0}$ \\
\hline Lauric (C12:0) & 0.05 & 0.33 \\
\hline Myristic (C14:0) & 1.29 & 0.99 \\
\hline Palmitic (C16:0) & 49.46 & 41.49 \\
\hline Stearic (C18:0) & 5.17 & 4.49 \\
\hline Arachidic (C20:0) & 0.45 & 0.40 \\
\hline Behenic (C22:0) & 0.22 & 0.09 \\
\hline Other & 0.23 & 0.19 \\
\hline Monounsaturated fatty acid & $\mathbf{3 5 . 0}$ & $\mathbf{4 1 . 7}$ \\
\hline Palmitoleic (C16:1 n-7c) & 0.14 & 0.17 \\
\hline Elaidic (C18:1 n-9t) & 0.67 & 0.11 \\
\hline Oleic (C18:1 n-9c) & 33.95 & 40.18 \\
\hline Eicosenoic (C20:1 n-9c) & 0.14 & 0.14 \\
\hline Other & 0.10 & 1.08 \\
https://biointerfaceresearch.com/ & &
\end{tabular}




\begin{tabular}{l|l|l}
\hline Fatty acid & PFAD $(\boldsymbol{\%})$ & CPO $(\boldsymbol{\%})$ \\
\hline Polyunsaturated fatty acid & $\mathbf{8 . 1}$ & $\mathbf{1 0 . 4}$ \\
\hline Linoleic $(\mathrm{C} 18: 2 \mathrm{n}-6 \mathrm{cc})$ & 7.70 & 9.95 \\
\hline Linolenic $(\mathrm{C} 18: 3 \mathrm{n}-3 \mathrm{ccc})$ & 0.23 & 0.28 \\
\hline Other & 0.20 & 0.12
\end{tabular}

\subsection{Biodiesel production from PFAD.}

3.2.1. Effect of methanol to PFAD molar ratio.

Biodiesel was produced from the PFAD from the palm oil refining plant at Oleen Co., Ltd., by the esterification method (Figure 3). The molecular weight of each product was computed based on the saponification value. The percentage of free fatty acid and the conversion of ester in the final products esterification, PFAD molar ratio is shown in Table 2.

It was found that the percentage conversion increased when increasing the molar ratio of free fatty acid and methanol (Table 2 ). This is the case, until a plateau at $\sim 97.51 \%$, for PFAD, with a free fatty acid of PFAD proportion in the range of $88.5 \pm 0.1$ to $2.16 \pm 0.01 \%$. However, we found the free fatty acid content decreases substantially to $\sim 2.16 \%$ of free fatty acid in the molar ratio of free fatty acid and methanol of 1:3.71. The theoretical molar ratio of methanol to PFAD is $1: 3$. This shows the governing effect of the molar ratio of free fatty acid and methanol in these complex polyphasic media due to the well-known physicochemical properties of the neoformed biodiesel [10-13, 15].

Table 2. Effect of PFAD to methanol molar ratio on esterification with $1.834 \% \mathrm{H}_{2} \mathrm{SO}_{4}$ catalyzed at $121{ }^{\circ} \mathrm{C}$ for 30 minutes.

\begin{tabular}{l|l|l} 
PFAD : Methanol (molar ratio) & FFA $(\%)$ & Conversion (\%) \\
\hline $1: 1.24$ & $13.34 \pm 0.02^{\mathrm{a}}$ & $84.61^{\mathrm{c}}$ \\
\hline $1: 2.47$ & $2.97 \pm 0.01^{\mathrm{b}}$ & $96.57^{\mathrm{b}}$ \\
\hline $1: 3.71$ & $2.16 \pm 0.01^{\mathrm{c}}$ & $97.51^{\mathrm{a}}$
\end{tabular}

* a Values within the same column having the same or without superscript are not significantly different ( $\mathrm{p}>0.05)$; Data is written as mean value and standard deviation.

\subsubsection{Effect of acid-catalyzed.}

The product containing the highest percentage of conversion was prepared again under the corresponding suitable conditions. The addition of methanol to the reaction mixture was investigated using a molar ratio of PFAD to methanol 1:3.71, and differing loads of acidcatalyzed $0.611-2.445 \%$ (Table. 3 ). When the acid-catalyzed was $1.223 \%$, the FAME conversion was higher than $90 \%$, and when the acid-catalyzed was $1.834 \%$, it was $97.56 \%$. This might be due to a diffusion limitation of methanol in the acid-catalyzed esterification on the PFAD. When the temperature was $121{ }^{\circ} \mathrm{C}$, the FAME conversion reached $97.56 \%$ in a reaction time of 30 minutes. The ester content could be reached more than $97 \%$ compared to the EN 14103 standard (96.5\% min).

Table 3. Effect of acid-catalyzed on esterification of PFAD to methanol molar ratio $1: 3.71$ at $121{ }^{\circ} \mathrm{C}$ for 30 minutes.

\begin{tabular}{l|l|l}
$\mathbf{H}_{2} \mathrm{SO}_{4}(\boldsymbol{\%})$ & FFA $(\%)$ & Conversion $(\%)$ \\
\hline 0.611 & $11.22 \pm 0.01^{\mathrm{a}}$ & $87.12^{\mathrm{c}}$ \\
\hline 1.223 & $6.67 \pm 0.01^{\mathrm{b}}$ & $90.02^{\mathrm{b}}$ \\
\hline 1.834 & $2.16 \pm 0.01^{\mathrm{c}}$ & $97.56^{\mathrm{a}}$ \\
\hline 2.445 & $2.15 \pm 0.01^{\mathrm{c}}$ & $97.25^{\mathrm{a}}$
\end{tabular}

* a Values within the same column having the same or without superscript are not significantly different ( $p>0.05$; Data is written as mean value and standard deviation. 


\subsubsection{Effect of reaction temperature.}

The product containing the highest conversion percentage was prepared again under the corresponding suitable conditions. The addition of methanol to the reaction mixture was investigated using a molar ratio of PFAD to methanol 1:3.71 and differing loads of temperature $70-130{ }^{\circ} \mathrm{C}$ (Table. 4). When the temperature was $70{ }^{\circ} \mathrm{C}$, the FAME conversion was lower than $90 \%$, and when the temperature was $121{ }^{\circ} \mathrm{C}$, the FAME conversion reached $97.56 \%$ in a reaction time of 30 minutes. The ester content could be reached more than $97 \%$ in comparison with the EN 14103 standard. However, in all temperature cases, the conversion of PFAD to FAME increased and was higher than $85 \%$. In addition, according to the kinetic theory, when the temperature is increased, the pressure also increases. As the particle gains kinetic energy, the mass transfer rate between the oil-methanol-catalyst phases increases, hence, producing FAME yield in a shorter time [16-20].

Table 4. Effect of temperature on esterification of PFAD to methanol molar ratio 1:3.71 with $1.834 \% \mathrm{H}_{2} \mathrm{SO}_{4}$ catalyzed for 30 minutes.

\begin{tabular}{l|l|l} 
Temperature $\left({ }^{\circ} \mathbf{C}\right)$ & FFA $(\%)$ & Conversion $(\%)$ \\
\hline 70 & $9.62 \pm 0.01^{\mathrm{a}}$ & $89.12^{\mathrm{c}}$ \\
\hline 100 & $6.17 \pm 0.01^{\mathrm{b}}$ & $93.02^{\mathrm{b}}$ \\
\hline 121 & $2.16 \pm 0.01^{\mathrm{c}}$ & $97.56^{\mathrm{a}}$ \\
\hline 130 & $2.34 \pm 0.01^{\mathrm{c}}$ & $97.35^{\mathrm{a}}$ \\
$*$ a Values within the same colum & having the same or without superscript are not significantly different
\end{tabular}
$(\mathrm{p}>0.05)$; Data is written as mean value and standard deviation.

\subsubsection{Effect of reaction time.}

To investigate the effect of the reaction time on the esterification reaction rate, a series of experiments has been performed by varying the reaction time from 10 to 30 minutes, as shown in Table 5. The FAME yield increased non-significantly after 15 minutes and remained constant when the reaction time was further increased to 30 minutes. Once the reaction system reached the desired temperature, the reaction was rapid, and the FAME yield immediately reached $97.11-97.31 \%$. This proves the potential of the acid catalyst under high temperature and pressure to shorten the time of the esterification reaction.

Table 5. Effect of time on esterification of PFAD to methanol molar ratio 1:3.71 with $1.834 \% \mathrm{H}_{2} \mathrm{SO}_{4}$ catalyzed at $121{ }^{\circ} \mathrm{C}$ for $10-30$ minutes.

\begin{tabular}{l|l|l|l} 
Time (minutes) & FFA $(\boldsymbol{\%})$ & Conversion $(\%)$ & FAME $(\%)$ \\
\hline 10 & $3.26 \pm 0.02^{\mathrm{a}}$ & $96.31^{\mathrm{b}}$ & $95.82^{\mathrm{b}}$ \\
\hline 15 & $2.34 \pm 0.01^{\mathrm{b}}$ & $97.35^{\mathrm{a}}$ & $97.11^{\mathrm{a}}$ \\
\hline 20 & $2.26 \pm 0.01^{\mathrm{b}}$ & $97.44^{\mathrm{a}}$ & $97.23^{\mathrm{a}}$ \\
\hline 25 & $2.20 \pm 0.01^{\mathrm{bc}}$ & $97.51^{\mathrm{a}}$ & $97.32^{\mathrm{a}}$ \\
\hline 30 & $2.16 \pm 0.01^{\mathrm{c}}$ & $97.56^{\mathrm{a}}$ & $97.31^{\mathrm{a}}$ \\
\multicolumn{2}{l}{ * V Values within the same column having the same or without superscript are not significantly different } \\
$(\mathrm{p}>0.05) ;$ Data is written as mean value and standard deviation.
\end{tabular}

In Thailand and Europe, biodiesel quality is assessed under the provisions and the requirements of quality standard EN 14214. Quality control was performed for the biodiesel produced under the optimum process conditions specified above (i.e., the molar ratio of PFAD to methanol 1:3.71 and obtained about $97.11 \%$ FAME yield at $121^{\circ} \mathrm{C}$, with $1.834 \% \mathrm{H}_{2} \mathrm{SO}_{4}$ catalyzed and 15 minutes reaction time), based on the European Standard EN 14214:2003. Density at $15{ }^{\circ} \mathrm{C}$, acidity number, methyl ester content, the content of monoglycerides, diglycerides, triglycerides, total and free glycerol were determined and measured. To further 
scale up biodiesel production from PFAD, all quality characteristics specified by the European standard EN 14214 should be determined.

\section{Conclusions}

Palm fatty acid distillate makes this by-product a suitable starting feedstock for biodiesel manufacture. The highest FAME yield produced was $97.11 \%$ in the presence of $1.834 \% \mathrm{H}_{2} \mathrm{SO}_{4}$ catalyst loading, 1:3.71 PFAD:methanol molar ratio, at $121{ }^{\circ} \mathrm{C}$ within 15 minutes. In conclusion, the acid catalyst with high temperature and pressure showed potential to enhance the esterification reaction rate of PFAD with low biodiesel production costs, high FAME yields, and short reaction times.

\section{Funding}

This research was funded by Prince of Songkla University, grant numbers 009/2563 and $002 / 2564$.

\section{Acknowledgments}

The authors wish to thank for Oleen Palm Oil plant (Samutsakorn, Thailand) for kindly providing the samples of palm oil and PFAD.

\section{Conflicts of Interest}

The authors declare that they have no conflict of interest. The funders had no role in the study's design, in the collection, analyses, or interpretation of data, in the writing of the manuscript, or in the decision to publish the results.

\section{References}

1. Office of Agricultural Economics. Palm oil. Phaholyothin Rd., Chatuchak, Bangkok 10900. 2021, www.oae.go.th.

2. Punvichai, T.; Pioch, D. Co-valorization of agro-industry by-products: effect of citrus oil on the quality of soap derived from palm fatty acid distillate and spent bleaching clay. Lett. Appl. NanoBioScience 2019, 8 , 571-575, https://doi.org/10.33263/LIANBS83.571575.

3. Punvichai, T.; Pioch, D. Covalorization of Palm Oil-Refining by-Products as Soaps. J. Am. Oil. Chem. Soc 2019, 96, 329-336, https://doi.org/10.1002/aocs.12193.

4. Punvichai, T.; Supranee, P.; Viboon, P; Prodpran, K. Two-step Biodiesel Production from Used Activated Bleaching Earth at Palm Oil Refining Plant. J. Biointerface Research in Applied Chemistry 2021, 11, 79737980, https://doi.org/10.33263/BRIAC111.79737980.

5. Akkarawatkhoosith, N.; Tongtummachat, T.; Kaewchada, A.; Jaree, A. Non-catalytic and glycerol-free biodiesel production from rice bran oil fatty acid distillate in a microreactor. Energy Conversion and Management: X 2021, 11, 100096, https://doi.org/10.1016/j.ecmx.2021.100096.

6. Encinar, J.M.; Nogales-Delgado, S.; Sánchez, N. Pre-esterification of high acidity animal fats to produce biodiesel: A kinetic study. Arabian Journal of Chemistry 2021, 14, 103048, https://doi.org/10.1016/j.arabjc.2021.103048.

7. Moradi, P.; Saidi, M.; Najafabadi, A.T. Biodiesel production via esterification of oleic acid as a representative of free fatty acid using electrolysis technique as a novel approach: Non-catalytic and catalytic conversion. Process Safety and Environmental Protection 2021, 147, 684-692, https://doi.org/10.1016/j.psep.2020.12.032.

8. dos Santos, P.R.S.; Voll, F.A.P.; Ramos, L.P.; Corazza, M.L. Esterification of fatty acids with supercritical ethanol in a continuous tubular reactor. The Journal of Supercritical Fluids 2017, 126, 25-36, https://doi.org/10.1016/j.supflu.2017.03.002. 
9. Idris, N.A.; Lau, H.L.N.; Wafti, N.S.A.; Mustaffa, N.K.; Loh, S.K. Glycerolysis of palm fatty acid distillate (PFAD) as biodiesel feedstock using heterogeneous catalyst. Waste and Biomass Valorization 2021, 12, 735744, https://doi.org/10.1007/s12649-020-00995-6.

10. Esan, A.O.; Olalere, O.A.; Gan, C.Y.; Smith, S.M.; Ganesan, S. Synthesis of biodiesel from waste palm fatty acid distillate (PFAD) and dimethyl carbonate (DMC) via Taguchi optimisation method. Biomass and Bioenergy 2021, 154, 106262, https://doi.org/10.1016/j.biombioe.2021.106262.

11. Collaço, A.C.A.; Aguieiras, E.C.G.; Santos, J.G.; de Oliveira, R.A.; Castro, R.P.V.; Freire, D.M.G. Experimental study and preliminary economic evaluation of enzymatic biodiesel production by an integrated process using co-products from palm (Elaeais guineensis Jaquim) industry. Industrial Crops and Products 2020, 157, 112904, https://doi.org/10.1016/j.indcrop.2020.112904.

12. Yeong, S.P.; San Chan, Y.; Law, M.C.; Ling, J.K. U. Improving Cold Flow Properties of Palm Fatty Acid Distillate Biodiesel Through Vacuum Distillation. Journal of Bioresources and Bioproducts 2021, https://doi.org/10.1016/j.jobab.2021.09.002.

13. Xu, H., Lee, U.; Wang, M. Life-cycle energy use and greenhouse gas emissions of palm fatty acid distillate derived renewable diesel. Renewable and Sustainable Energy Reviews 2020, 134, 110144, https://doi.org/10.1016/j.rser.2020.110144.

14. AOCS. Official Methods \& Recommended Practices, 4-th ed. American Oil Chemists Society USA 1993.

15. Tajima, H.; Abe, M.; Komatsu, H.; Yamagiwa, K. Feasibility of additive winterization of biodiesel fuel derived from various eatable oils and fat. Fuel 2021, 305, 121479, https://doi.org/10.1016/j.fuel.2021.121479.

16. Gupta, A.R.; Rathod, V.K. Biodiesel synthesis from palm fatty acid distillate using enzyme immobilized on magnetic nanoparticles. SN Applied Sciences 2020, 2, 1778, https://doi.org/10.1007/s42452-020-03338-1.

17. Ibrahim, S.F.; Asikin-Mijan, N.; Ibrahim, M.L.; Abdulkareem-Alsultan, G.; Izham, S.M.; Taufiq-Yap, Y.H. Sulfonated functionalization of carbon derived corncob residue via hydrothermal synthesis route for esterification of palm fatty acid distillate. Energy Conversion and Management 2020, 210, 112698, https://doi.org/10.1016/j.enconman.2020.112698.

18. Wang, Y.T.; Cong, W.J.; Zeng, Y.N.; Zhang, Y.Q.; Liang, J.L.; Li, J.G.; Jiang, L.Q.; Fang, Z. Direct production of biodiesel via simultaneous esterification and transesterification of renewable oils using calcined blast furnace dust. Renewable Energy 2021, 175, 1001-1011, https://doi.org/10.1016/j.renene.2021.05.013.

19. Zhang, H.; Tian, F.; Xu, L.; Peng, R.; Li, Y.; Deng, J. Batch and continuous esterification for the direct synthesis of high qualified biodiesel from waste cooking oils (WCO) with Amberlyst-15/Poly (vinyl alcohol) membrane as a bifunctional catalyst. Chemical Engineering Journal 2020, 388, 124214, https://doi.org/10.1016/j.cej.2020.124214.

20. Zhang, H.; Zhang, L.L.; Tan, X.; Li, H.; Yang, S. Catalytic high-yield biodiesel production from fatty acids and nonfood oils over a magnetically separable acid nanosphere. Industrial Crops and Products 2021, 173, 1-14, https://doi.org/10.1016/j.indcrop.2021.114126. 